\title{
A IDENTIDADE COMO METAMORFOSE: PROEJA ENTRE O PRESCRITO E O VIVIDO
}

\author{
Tatiana de Santana Vieira ${ }^{1}$, Eliesér Toretta Zen² ${ }^{2}$, Bruno dos Santos Prado Moura ${ }^{3}$
}

Pós-graduação Lato Sensu em PROEJA, Instituto Federal do Espírito Santo

E-mail: tattisantana@yahoo.com.br, elieserzen@ifes.edu.br, bruno.moura@ifes.edu.br

\begin{abstract}
RESUMO
O artigo é resultado do trabalho monográfico realizado durante o Curso de Pós-Graduação Lato Senso em Educação Profissional e Técnica Integrada à Educação Básica na Modalidade de Jovens e Adultos do Instituto Federal de Educação do Espírito Santo (IFES), cujo objetivo foi analisar em que medida o Programa Nacional de Integração da Educação Profissional com a Educação Básica na Modalidade de Educação de Jovens e Adultos (PROEJA) do IFES no Campus Vitória possibilita a construção de uma identidade dos seus alunos e alunas com o Programa e a instituição. A investigação foi localizada em uma realidade específica, sendo assim, optou-se pela linha de pesquisa quanti-qualitativa, a partir da qual se enfatizou o formato de investigação da História Oral. Foram utilizados questionários e entrevistas semiestruturadas como instrumentos de coleta de dados com os quais identificamos e selecionamos os sujeitos da pesquisa entre os estudantes do 50 ao 8o módulos dos cursos de Edificações, Segurança do Trabalho e Metalurgia e Materiais do PROEJA IFES Campus Vitória.
\end{abstract}

Palavras-chaves: estudos culturais, diferença, diversidade, identidade institucional, PROEJA.

\section{INTRODUÇÃO}

O Programa Nacional de Integração da Educação Profissional com a Educação Básica na Modalidade de Educação de Jovens e Adultos (PROEJA) instituído pelo Decreto $n^{\circ}$ 5.840/06 completa quatro anos e passa por um momento no qual analisar sua trajetória faz-se necessário. Neste sentido, o presente artigo, resultado de uma pesquisa monográfica realizada durante o Curso de Pós-Graduação Lato Senso em Educação Profissional e Técnica Integrada à Educação Básica na Modalidade de Jovens e Adultos do Instituto Federal de Educação do Espírito Santo (Ifes), pretende somar às discussões sobre o Programa, examinando em que medida o PROEJA no Campus Vitória do Ifes possibilita a construção de uma identidade de seus alunos(as) com o Programa e a Instituição.

A pesquisa pretende contribuir com a discussão para efetivar o PROEJA como política pública em nosso país. Em nossa concepção, para que isto se torne realidade, precisamos compreender as necessidades dos principais sujeitos deste processo: os estudantes; conhecê-los de perto, resgatar suas histórias, seus conhecimentos, ouvir seus anseios e valorizar seus sonhos. Não podemos interferir no passado do aluno e da aluna do PROEJA, mas como educadores, cientes de nosso papel social e político, devemos contribuir para que futuro desses seja um tempo de esperanças e de realizações. Afinal, a vida é como um papel em branco escrito pela tinta da experiência do ser humano no tempo, com momentos de continuidades e, principalmente, de mudanças. Com os protagonistas de nosso estudo, o percurso é semelhante porque eles são partes essenciais para a consolidação plena do PROEJA no Ifes.

A percepção da importância dos jovens e adultos do/para o PROEJA é objeto de estudo recorrente entre estudantes da Especialização em Educação Profissional Técnica Integrada à Educação Básica na Modalidade de Jovens e Adultos, pesquisadores do Grupo de Pesquisa Interinstitucional PROEJA/CAPES/SETEC/ES-PPGE/CE/UFES-IFES e de professores, enfim, daqueles que pensam e fazem o PROEJA. Neste contexto, o presente trabalho pretende contribuir para efetivação do PROEJA no Ifes Campus Vitória como uma política afirmativa para a educação de jovens e adultos trabalhadores, enquanto sujeitos coletivos de direitos (ARROYO, 2007).

Recorremos a um referencial teórico multidisciplinar para direcionar as discussões conceituais sobre as identidades. As teorizações de Silva, Woodward e Hall (2008), destacaram a perspectiva da identidade nos

\footnotetext{
${ }^{1}$ Mestranda em Educação pelo Programa de Pós-Graduação em Educação da UFES.

${ }^{2}$ Mestre em Educação pelo Programa de Pós-Graduação em Educação da UFES, professor do Campus Vitória do IFES.

${ }^{3}$ Mestre em Educação pelo Programa de Pós-Graduação em Educação da UFES, professor do Campus Nova Venécia do IFES.
} 
Estudos Culturais. Também foram de grande valor as contribuições de Castoriadis (1992), Ciampa (2001), Freire (1983; 1996) e Heller (1992) para desenvolvemos a pesquisa tendo a identidade dos sujeitos do PROEJA no Ifes Campus Vitória como o locus central. Fundamentamo-nos na História Oral para dialogarmos com os estudantes, uma vez que consideramos relevante os próprios sujeitos serem os interlocutores de suas vivências. A análise dos dados foi realizada a partir do método quanti-qualitativo. Os resultados apontaram contribuições significativas da vivência dos estudantes no PROEJA Ifes Campus Vitória em suas subjetividades emancipatórias para a continuidade de suas trajetórias de vida.

\section{TECENDO REDES DE SIGNIFICADOS}

Este artigo, que discute a possível construção de uma identidade dos alunos(as) com o PROEJA Ifes Campus Vitória, ganha vida a partir de um diálogo multidisciplinar. Diversas áreas do pensamento científico contribuíram com a discussão, notadamente estudiosos da Educação (FREIRE, 1983; 1996; 2005), da Filosofia (CASTORIADIS, 1982; HELLER, 1992), da Psicologia Social (CIAMPA, 2001) e dos Estudos Culturais (HALL, 2006; SILVA, 2007; 2008).

No que tange à relevância da identidade na atuação simbólica, Hall (apud WOODWARD, 2008, p. 08) salienta o uso da representação pelos grupos sociais para classificar o mundo e as relações no seu interior. Esta definição adiciona significado à reflexão desenvolvida acerca da aquisição de sentido, pelas identidades, por meio da linguagem e dos sistemas simbólicos pelos quais elas são representadas. Ainda sobre a construção das identidades, Woodward (2008) enfatiza sua vertente relacional, a qual para existir depende de algo exterior, de outra identidade, em que se afirma por meio das diferenças entre o eu e o outro. Neste sentido, a identidade pode ser definida sob duas perspectivas: a essencialista ou a não-essencialista (WOODWARD, 2008). A essencialista é norteada por um conjunto cristalino autêntico de características partilhadas em determinado grupo sem alteração ao longo do tempo. Enquanto a perspectiva não-essencialista ou construcionista focaliza as diferenças, as características comuns ou compartilhadas, as transformações, o que é próprio de determinado grupo ou de outros grupos étnicos.

Com o objeto de estudo (estudantes do PROEJA Ifes Campus Vitória) da pesquisa, trabalhamos com a segunda perspectiva, porque ela sugere a construção da identidade de um determinado grupo a partir da diferença em relação aos outros e esta posição vai ao encontro da situação vivenciada pelos alunos e alunas do PROEJA. Ser do PROEJA no Ifes é não ser do Técnico Integrado "regular" ou do Técnico Subsequente e, logo, é fazer parte de uma série de estigmas (o aluno que não aprende, por exemplo). Outro estudioso que contribui com a discussão sobre identidade é Ciampa (2001).

Em sua tese o referido pesquisador, compreende a identidade enquanto metamorfose, uma vez que o ser humano é um ser que se (re)constrói no decorrer de sua trajetória no mundo, afinal:

Cada individuo encarna as relações sociais, configurando uma identidade pessoal. Uma história de vida. Um projeto de vida. Uma vida-que-nem-sempre-é-vivida, no emaranhado das relações sociais. [...] No seu conjunto, as identidades constituem a sociedade, ao mesmo tempo em que são constituídas, cada uma por ela (CIAMPA, 2001, p. 127).

Ciampa (2001) desenvolve seu pensamento a partir de três categorias essenciais na Psicologia Social para estudar o homem: atividade, consciência e identidade. Com a articulação dessas categorias demonstra que a identidade assume forma de personagem - pai, mãe, estudante, trabalhador(a), filho(a) - conforme o contexto no qual o indivíduo está inserido. Assim, ele (o sujeito) deve ser visto como relação e não como ser isolado, pois deve ser entendido a partir do meio social ao qual pertence e da posição que exerce neste meio em um determinado tempo. Neste contexto, a identidade é histórica, uma vez que os homens são atores e autores de suas histórias e "a História, então, é a história da auto-produção humana, o que faz do Homem um ser de possibilidades, que compõe sua essência histórica" (CIAMPA, 2001, p. 172). Desse modo, não podemos negar que a formação da identidade está intrinsecamente ligada à conexão do ser humano com o mundo exterior.

Na visão de Heller (1992), o mundo exterior é representado pelas relações sociais, históricas e culturais. Para a filósofa, a essência humana é genérica e particular ao mesmo tempo. A pessoa assume estereótipos, analogias e esquemas anteriormente elaborados pelo meio no qual ela cresce e, ao mesmo tempo, desenvolve-se no campo singular, assim "todo homem é, ao mesmo tempo, ente particular-individual e ente humano-genérico, ou seja, uma 'singularidade' e simultaneamente, uma parte orgânica da humanidade, da história humana” (HELLER, 1992, p. 47). A formação da identidade se dá entre o eu e o outro ou o eu e o meio, no momento em que o homem reconhece a si mesmo e ao mundo através do espelho dos demais. 
Diante do exposto, entendemos que a sociedade mantém um papel fundamental na formação da subjetividade humana. Sendo assim, o homem é um ser que se constrói e se reconstrói em uma determinada comunidade envolta em símbolos e representações.

Em busca de uma fundamentação a respeito da influência dos símbolos e representações na sociedade, destacamos o pensamento de Castoriadis (1982) sobre esta questão. Segundo o autor, o mundo social-histórico está entrelaçado a sistemas simbólicos onde a função da instituição consiste em ligar os símbolos (significantes) aos significados (representações, ordens). A instituição é entendida como "uma rede simbólica, socialmente sancionada, onde se combinam em proposições e em relações variáveis um componente funcional e um componente imaginário" (CASTORIADIS, 1982, p.159).

O encontro da instituição escola com os alunos e alunas é instigado por Freire (1996). Na reflexão freiriana, o educador que se quer fazer progressista, não pode focar o processo de ensino-aprendizagem somente no espaço temporal de sua aula. Segundo Freire quando o educador compreende que "foi aprendendo que percebemos ser possível ensinar" (1996, p.44), valorizaria as experiências e conhecimentos informais aprendidos nos diversos espaços de convívio social frequentado pelo educando. Tal olhar diferenciado encara o educando e a si mesmo (educador) como um ser completo, portador em uma identidade cultural (na dimensão individual e de classe), um personagem histórico pensante, criador e realizador de sonhos.

Partimos dessas teorizações para desenvolver o trabalho, no qual a escola se colocou como espaço formador de símbolos que intervieram na formação das subjetividades dos indivíduos (estudantes). Desse modo, a intensidade como esta intervenção ocorreu, mesmo que se apresentasse naturalizada, evidenciou a força exercida pela instituição no imaginário do grupo. Essa reflexão é importante, uma vez que analisamos a influência do simbolismo que envolve o Ifes enquanto instituição, na identidade dos alunos e alunas do PROEJA.

A pesquisa desenvolvida elaborou uma reflexão sobre a identidade dos estudantes sujeitos do PROEJA Ifes Campus Vitória nos cursos de Edificações, Segurança do Trabalho e Metalurgia e Materiais entre o 5으 e 8은 módulos no período 2009/02. Utilizamos a metodologia da História Oral, uma vez que ela possibilitou aos sujeitos da pesquisa reconstruírem e contarem suas trajetórias de vida sem intermediários. Este ato de incessante reconstrução na história de cada pessoa é a metamorfose vivenciada, porém nem sempre percebida, na trajetória da vida. No cotidiano há uma força que impede o sujeito de atender às necessidades do momento (trabalhar, estudar, cuidar da família), as quais interferem no movimento de construção/formação de sua identidade. A formação das identidades é um processo simultâneo que faz o ser humano buscar a si mesmo na individualidade e no coletivo (seja pela identificação das semelhanças ou pela afirmação das diferenças) e por meio deste ele atua como sujeito de construção da História (DELGADO, 2006).

$\mathrm{Na}$ análise dos dados, consideramos o método quanti-qualitativo mais adequado à investigação desenvolvida, em razão da sua vertente multimetodológica, sua flexibilidade e diversidade (MAZOTTI; GEWANDSZNAIDER, 1998). Como categoria de pesquisa, selecionamos o estudo de caso, isto porque nosso olhar estava voltado para análise de uma determinada unidade (estudantes do PROEJA Ifes Campus Vitória).

Os caminhos percorridos para tentar responder às questões levantadas acerca da identidade dos alunos e alunas no PROEJA do Ifes Campus Vitória se iniciaram com a revisão de literatura, em que buscamos o aporte teórico-metodológico para a pesquisa, assim como outras referências sobre EJA e PROEJA, inclusive em monografias das turmas anteriores (2007 e 2008) do Curso de Pós-graduação lato senso em Educação Profissional Técnica Integrada à Educação Básica na Modalidade de Jovens e Adultos do Ifes. A revisão de literatura mostrou-se uma etapa fluida na construção da pesquisa; ela se desenvolveu à medida em que o trabalho avançava e surgiam novos pontos que precisavam ser discutidos e/ou aprofundados.

O nosso estudo foi realizado com utilização de dois instrumentos de coleta de dados: inicialmente aplicamos um questionário, a partir do qual identificamos e selecionamos os sujeitos da pesquisa; posteriormente coletamos suas histórias, utilizando da História Oral ${ }^{4}$.

Os instrumentos utilizados na coleta de dados foram essenciais para alcançar o objetivo de analisar a possibilidade de construção de uma identidade dos alunos e alunas no PROEJA do campus Vitória do Ifes. No primeiro momento, escolhemos o questionário, pela sua possibilidade de atingir o maior número de pessoas possível. $O$ instrumento foi composto de 23 questões, dentre as quais 21 foram fechadas e duas abertas, sendo a última subdividida em quatro letras $(a, b, c, d)$. Este questionário foi aplicado a 62 estudantes dos cursos do PROEJA Ifes Campus Vitória matriculados entre os 5ㅇ e os 8ㅇ módulos, correspondentes à parte técnica dos

\footnotetext{
${ }^{4}$ Norteamos nossa análise a partir do conceito de História Oral desenvolvido por Delgado (2006). Para a historiadora, esse método é interdisciplinar e dialoga com as intersubjetividades do tempo passado e do presente. Sendo a memória a essência do resgate dos tempos vividos, por meio dos depoimentos orais, ela resguarda "as dimensões do tempo individual (vida privada - roteiro biográfico) e do tempo coletivo (social, nacional, internacional)” (DELGADO, 2006, p. 16) do depoente.
} 
cursos $^{5}$, no período de 2009/02. Pesquisaram-se os alunos dos cursos de Edificação, Segurança do Trabalho e Metalurgia e Materiais no segundo semestre de 2009. O curso com maior número de questionários aplicados foi o de Segurança do Trabalho, com 25 estudantes, seguido de Edificações com 19 e Metalurgia e Materiais com 18.

Os dados coletados demonstraram ser a clientela do PROEJA no Ifes Campus Vitória bastante jovem. 0 próximo gráfico contempla a faixa etária dos alunos. Vejamos:

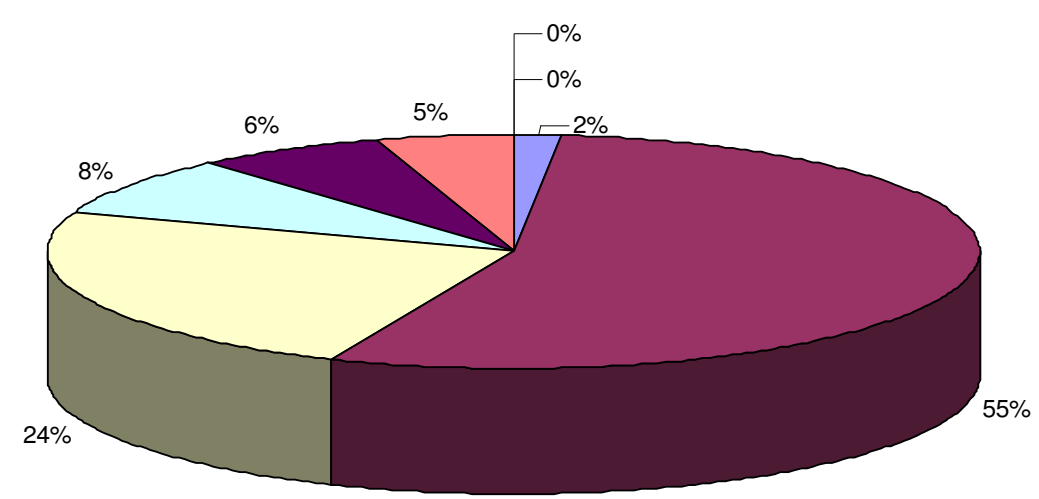

$\square$ Entre 18 e 20 anos

$\square$ Entre 21 e 25 anos

$\square$ Entre 26 e 30 anos

$\square$ Entre 31 e 35 anos

- Entre 36 e 40 anos

$\square$ Entre 41 e 45 anos

$\square$ Entre 46 e 50 anos

$\square$ Acima de 51 anos

\section{Gráfico 01 - Faixa etária.}

A faixa etária dominante no grupo fica entre 21 e 25 anos, mais da metade dos estudantes (55\%). Esta realidade do PROEJA no Ifes repercute o movimento conhecido como juvenização da EJA, representado por "uma leva nova de jovens urbanos que buscam na EJA uma alternativa para dar prosseguimento à sua vida escolar" (VOLPE [s.d], p. 02), fato cada vez mais comum nos corredores da escola.

Em relação ao processo de escolarização dos estudantes pesquisados, os dados demonstram ser a maioria dos educandos do PROEJA proveniente do ensino público. Dentre os 62 estudantes, 50 (81\%) vieram de escolas públicas e apenas dez (16\%), de escolas particulares. Vejamos no gráfico abaixo a escolaridade do alunado do PROEJA Ifes Campus Vitória, antes de ingressarem no curso.

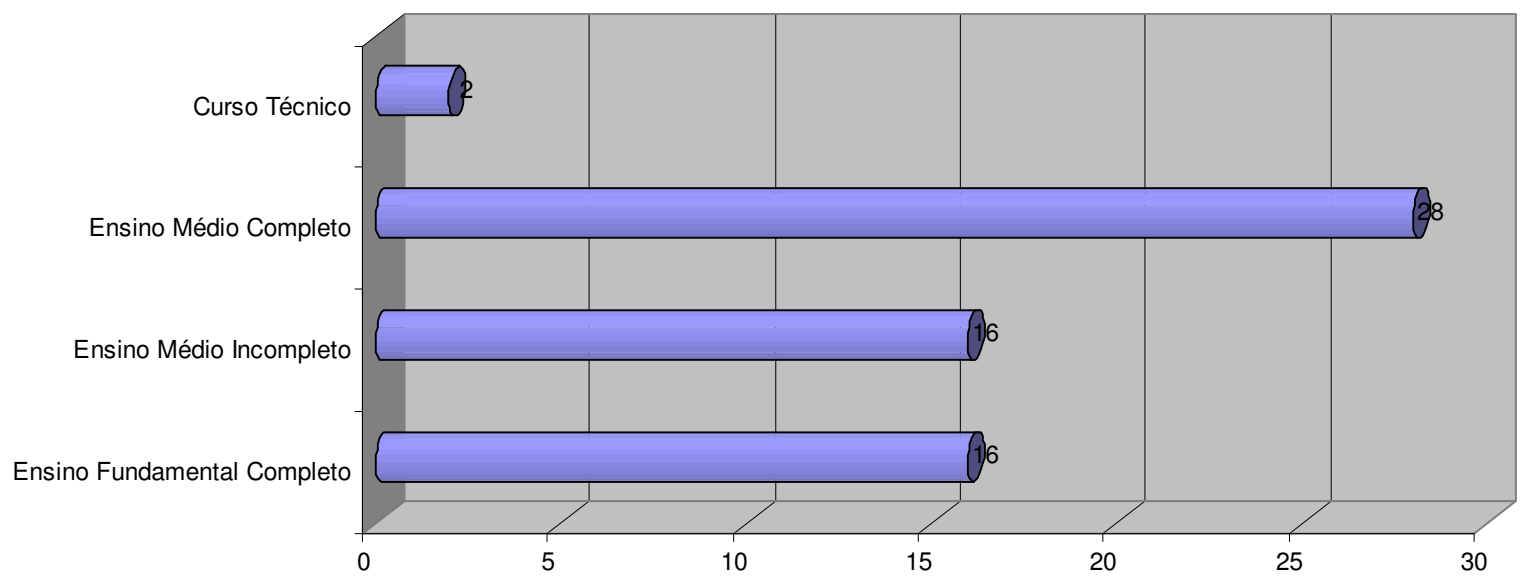

\section{Gráfico 02 - Escolaridade.}

\footnotetext{
${ }^{5}$ A estrutura do PROEJA no Ifes entre 2006 e 2009 dividia os cursos em oito módulos semestrais, totalizando quatro anos. Nos dois primeiros anos eram contempladas as disciplinas gerais do Ensino Médio e nos dois últimos as disciplinas técnicas profissionalizantes. A reformulação do Projeto Político Pedagógico (PPP) realizada em 2009 modificou a organização dos cursos do PROEJA a fim de promover a interdisciplinaridade, mesclando nos períodos/anos as disciplinas gerais e técnicas. Para conhecer melhor este processo ver: Moura et al. (2010).
} 
Os dados revelaram uma constatação surpreendente: somente 16 (26\%) alunos(as) concluíram apenas o ensino fundamental (pré-requisito para participar do processo seletivo) antes de ingressar no PROEJA; 16 (16\%) tinham ensino médio incompleto; 28 (45\%) o ensino médio completo e dois (3\%) curso técnico, 24 (39\%) já estudaram na modalidade EJA ou fizeram Supletivo. Chamamos atenção para o fato de a maioria dos estudantes já haver cursado o ensino médio. Se estes sujeitos já concluíram a educação básica, por que voltaram? Será que tiveram uma formação deficiente ou viram no PROEJA um caminho mais fácil para chegar ao ensino técnico? Formular qualquer teoria aqui seria precipitado, pois apenas cinco alunos (8\%) disseram que escolheram o curso por ser menos concorrido que o curso técnico subsequente, além disto, sete (11\%) afirmaram que marcaram a opção errada durante a inscrição.

Com o questionário percebemos a diversidade presente em todo momento nas salas de aula, onde nos deparamos também com sujeitos produtores de saberes oriundos do cotidiano e das práticas sociais. Portanto, entendemos que a diversidade, característica da EJA, deve ser considerada e respeitada pelos educadores que irão trabalhar com esta modalidade de educação.

\section{TRAJETóRIAS DE VIDA E O MOVIMENTO DA CONSTRUÇÃo dAS SUBJETIVIDADES dOS(AS) ALUNOS(AS) Do PROEJA}

Apresentaremos as análises realizadas a partir das narrativas de vida de seis estudantes do PROEJA Ifes Campus Vitória, selecionados entre os sujeitos que responderam ao questionário. Conhecer essas histórias era um dos objetivos centrais da pesquisa e diante delas nos indagamos: quais questões das vidas desses alunos e alunas vieram à baila?

Nas falas dos sujeitos evidenciamos constantes rupturas em suas histórias, condicionantes dos caminhos seguidos ao longo de suas vidas. O termo ruptura pode ser substituído pela metamorfose, utilizado por Ciampa (2001) e presente nessa discussão. Quando nos referimos à metamorfose, falamos de transformação e de superação.

Do ponto de vista biológico, enquanto ser vivo, mantermo-nos inalterados é impossível; nascemos, desenvolvemo-nos e, fatalmente, morreremos. É um processo inevitável. Segundo Ciampa, algo semelhante acontece com a identidade. As pessoas não conseguem evitar a transformação ao longo de suas vidas, e é neste movimento (em que o ser humano vai se reconstruindo durante sua trajetória no mundo) que as identidades vão sendo construídas pelas subjetividades, nas relações sociais (HELLER, 1992).

Notamos, durante o desenvolvimento do estudo, diversos campos sociais ${ }^{6}$ interferindo constantemente nas subjetividades dos estudantes. Neste contexto, as identidades do grupo estudado são "resultados de um processo de produção simbólica e discursiva" (SILVA, 2008, p. 81), que vão sendo definidas no individual e no coletivo, nos percursos de suas vidas.

Um dos campos sociais formador das subjetividades dos alunos é a escola. As histórias educacionais dos sujeitos quase nunca foram traçadas linearmente, somente Maria ${ }^{7}$ e Elena tiveram uma trajetória escolar regular. Sara foi a última a iniciar a educação formal, com 15 anos. Enquanto Miguel, Sebastião e Eduardo afastaram-se dos estudos quando constituíram família. Por coincidência somente os homens entrevistados eram casados e todos ressaltaram a dificuldade em conciliar o trabalho, a família e a escola. Neste aspecto, destacamos a contribuição de Woodward (2008) ao demonstrar ser uma das características da vida moderna a difícil tarefa de estabelecer fronteiras entre múltiplas identidades vividas, aqui representadas nos papéis de pai, homem e trabalhador ou de esposa, mulher, filha e trabalhadora.

Verificamos que, seja para concluir ou complementar os estudos, a educação "implica uma busca realizada por um sujeito" (FREIRE, 1983, p. 28), busca permanente em ser mais, de um ser que se sabe inacabado. A inconclusão do ser, para Freire (1996; 2005), é própria da experiência vital inerente aos seres vivos. Todavia, o homem é o único ser consciente de seu inacabamento e por ter esta noção pode ir além, em um permanente processo social de busca de se perceber no mundo, com uma nova postura, de quem nele se insere

como seres que caminham para frente, que olham para frente; como seres a quem o imobilismo ameaça de morte; para quem o olhar para trás não deve ser uma forma nostálgica de querer voltar, mas um modo melhor de conhecer o que está sendo, para melhor construir o futuro. Daí que se identifique com o movimento permanente em que se acham inscritos os homens, como seres que se sabem inconclusos; movimento que é

\footnotetext{
${ }^{6}$ Para Pierre Bourdieu (1984, apud WOODWARD, 2008, p. 30) os indivíduos vivem dentro de diferentes instituições (família, partidos políticos, instituições educacionais) que constituem os "campos sociais".

${ }^{7}$ Para preservar os sujeitos da pesquisa, identificamos os estudantes com nomes fictícios, onde a primeira letra corresponde ao curso: E Edificações; S - Segurança do Trabalho e M - Metalurgia e Materiais.
} 
histórico e que tem o seu ponto de partida, o seu sujeito, o seu objetivo (FREIRE, 2005, p. 8485).

Ao saber que "sou o que estou-sendo" (CIAMPA, 2001, p. 172), a pessoa percebe que veste de uma personagem, a qual representa. A ação de representar caracteriza a categoria da "atividade", desenvolvida por Ciampa, em que o sujeito é o que faz (ou representa) no tempo presente. Ao saber-se como ser em constante processo de mudança, o indivíduo adquire a "consciência", outra categoria trabalhada por Ciampa, da concretude da identidade e ao mesmo tempo, percebe com possibilidade e não determinismo. Nas colocações dos estudantes estas análises emergem, por exemplo, ao dizer: "acho que a vida da gente tem que ser assim, todo mundo tem que ter oportunidade, tem que amadurecer" e com estas falas trazem para a realidade estas reflexões. Do mesmo modo, Eduardo critica seus parentes que "não saem daquela mesmice". O termo "amadurecer" e a negação à "mesmice", evidenciam a consciência dos alunos de que eles não podem ficar estáticos, eles aprendem com seu passado, mas não estão presos a ele. Seguindo esta direção, a consciência leva o homem a se apropriar da sua vida como possibilidade histórica e neste jogo "o fatalismo cede, então, lugar ao ímpeto de transformação e de busca, de que os homens se sentem sujeitos" (FREIRE, 2005, p. 85).

Com base nas informações coletadas, percebemos que os alunos(as) ouvidos atribuíram à experiência no PROEJA uma transformação positiva em suas vidas. A complexidade do cotidiano social dos sujeitos permeia o espaço escolar. As barreiras para permanecer e concluir o curso existem: o cansaço de Sebastião, a perda de pessoas próximas e queridas de Maria e Elena, a jornada dupla (escola e trabalho) ou tripla (escola, trabalho e família) de todos aparecem nas palavras, nos gestos e nos rostos dos estudantes, mas a vontade de crescer e construir um futuro melhor do que foi o passado não os deixam desistir. O encontro com a auto-estima (Sara) e as oportunidades de crescimento profissional (Miguel e Eduardo) podem ser falas pontuais, mas a perspectiva de um futuro melhor é constante. Nenhum entrevistado demonstrou pessimismo ou arrependimento em participar do PROEJA, ao contrário, em todos os relatos sobressaíram o otimismo e a esperança no futuro. Logo, ao PROEJA, enquanto campo social compartilhado pelos estudantes, podemos aferir representações simbólicas e significados sociais contribuintes para a (re)construção da identidades dos educandos.

No entanto, afirmar as conquistas conferidas ao PROEJA Ifes Campus Vitória pelos estudantes não significa que eles foram incluídos na instituição, suas próprias histórias nos levam a pensar sobre a abrangência dessa inclusão. Mesmo as colocações de alguns estudantes evidenciando o não-preconceito ou a nãodiscriminação na escola são parciais. Sara, por exemplo, afirmou não haver preconceito dentro da instituição e logo depois relatou casos de posturas autoritárias e conservadoras de professores. Miguel já foi mais enfático e descreveu "certo preconceito" de professores que não queriam trabalhar com o PROEJA. Eduardo ponderou entre professores que "colaboraram" e outros que "não perdoavam" e enfatizou a dificuldade de estudar em uma turma mista de alunos do técnico subsequente e do PROEJA ${ }^{8}$.

Notamos, nesse último exemplo, que o ritmo de ensino da sala de aula era ditado pela aprendizagem dos alunos "regulares" do curso técnico subsequente. Quando a escola uniu em uma mesma sala modalidades de ensino diferentes, cujos sujeitos têm características particulares, o lado mais "fraco" do processo saiu prejudicado. A turma do PROEJA foi misturada à do subsequente e as especificidades do Programa diluídas e desprezadas. Alguns profissionais do Instituto consideram o alunado da escola homogêneo, nesta percepção "os alunos seriam todos iguais, não sendo consideradas assim as especificidades dos sujeitos da EJA, desmerecendo a necessidade de um tratamento didático-pedagógico diferenciado" (MOURA et al, 2010, p. 08).

Alguns alunos como Eduardo incorporaram a visão da escola. Este estudante, quando respondeu ao questionário, disse que "alguns professores também discriminam, cobram muito. Querem que façamos como os 'garotos' que apenas estudam!" e na entrevista afirmou que "o professor não podia ficar amarrado na matéria [...] só com aquele grupinho do PROEJA com dificuldade [...]". Em sua fala a turma se transformou em um "grupinho", atrapalhando o desenvolvimento da classe, dos "garotos".

A força da linguagem na constituição das identidades é um fator para o qual se deve voltar a atenção. Palavras e expressões surgem aparentemente descrevendo uma situação, mas podem camuflar uma performatividade ${ }^{9}$ (BUTLER, 1999 apud SILVA, 2008, p. 92). Este conceito revela que

\footnotetext{
${ }^{8}$ Essa dinâmica é proposta pela instituição para tentar minimizar o "problema" da evasão no decorrer do curso. Desse modo, a escola une as classes do PROEJA, a partir do 5o módulo, com turmas dos Cursos Técnicos Subsequente, mediante edital das turmas intituladas "Cursos Técnicos PROEJA" (IFES, 2009).

${ }_{9}^{9}$ Performatividade: conceito desenvolvido inicialmente por Austin (1998), refere-se às "proposições que não se limitam a descrever um estado de coisas. Ao serem pronunciadas, essas proposições fazem com que algo se efetive, se realize [...] são exemplos típicos de proposições performativas: 'eu vos declaro marido e mulher', 'prometo que te pagarei no fim do mês', 'declaro inaugurado este monumento'” (SILVA, 2008, p. 92-93).
} 
ao dizer algo sobre certas características identitárias de algum grupo social, achamos que estamos simplesmente descrevendo uma situação existente, um "fato" no mundo social. 0 que esquecemos é que aquilo que dizemos faz parte de uma rede mais ampla de atos linguísticos que, em seu conjunto, contribui para definir ou reforçar a identidade que supostamente apenas estamos descrevendo (SILVA, 2008, p. 93).

Assim, a referência aos alunos do PROEJA como "grupinho" ou "atrasados" não se está simplesmente descrevendo os estudantes, mas reforçando a negatividade da identidade PROEJA no Ifes. Enquanto prevalecer na escola esta ideia negativa em relação à diversidade, as diferenças do grupo estudantil continuarão a causar a marginalização dos sujeitos do PROEJA. A materialidade deste processo é a permanência da evasão, ou melhor, da exclusão dos estudantes da instituição. Se não é fácil "entrar" na escola, tarefa mais árdua é "permanecer", concluem os estudantes. Diante do exposto, entendemos ser fundamental a mudança do olhar (dos profissionais) do Instituto sobre a diversidade. Encarar a diversidade a partir de uma outra perspectiva possibilitará ver que dela também pode aflorar positivamente a "heterogeneidade e hibridismo, sendo vista como enriquecedora" (WOODWARD, 2008, p. 50).

Tal como acontece com a diversidade, o posicionamento do sujeito em relação à identidade depende de vários fatores, dentre eles a relação particular-individual de cada aluno e aluna e a relação social-coletiva com os outros e a Instituição. Notamos estar o PROEJA Ifes Campus Vitória no limiar, na linha de fronteira, onde se evidencia a instabilidade da identidade (SILVA, 2008). Este espaço escolar ainda se apresenta como "não-lugar" aos sujeitos do PROEJA (OLIVEIRA, 2008). No entanto, não podemos desprezar a existência de ações teóricas e práticas compromissadas em consolidá-lo como "lugar" possível e tangível.

Mais uma vez devemos reportar às falas dos estudantes para ilustrar essas colocações. O Projeto Integrador $^{10}$, por exemplo, permeia a discussão de duas alunas (Maria e Elena) sobre a importância do PROEJA para sua formação. Enquanto uma (Maria) superou a timidez a outra (Elena) iniciou sua política no PROEJA a partir de críticas ao referido Projeto. As estudantes evidenciam uma posição comum aos alunos do PROEJA. Antes mesmo de desenvolverem o projeto, e, portanto, não o conheciam, eram influenciadas por terceiros e as notícias que tinham sobre o mesmo eram aterrorizantes, logo, falar em público ou apresentar para uma banca de professores da escola, realmente parecia "pedir de mais". Depois da experiência concretizada, o Projeto foi (re)significado, representando a superação de desafios pessoais e pedagógicos. Para esses estudantes, 0 Projeto Integrador passou a demarcar a possibilidade de resolver outros desafios que a vida lhes impõe.

Os estudantes entrevistados concluíram ou estão concluindo o curso com novos horizontes profissionais e, sobretudo, pessoais. A colocação de Miguel, de que se formar "vai ser uma vitória e tanto" poderia, sem prejuízos, ser de qualquer outro estudante entrevistado. Eduardo, o único entrevistado formado, já constatou que sua vida "mudou completamente", principalmente em relação às condições de vida de sua família, em outras palavras, sua vitória já foi alcançada.

\section{ALgumas ConsideraçõEs}

Com a pesquisa, percebemos ser cada vez mais urgente e necessário ouvir os estudantes do PROEJA. Sua diversidade e multiplicidade de experiências, dentro e fora da escola, tornam-se fundamentais para o desenvolvimento do Programa no Instituto. Como salienta Ferreira (2008, p. 15):

Considerar que na educação escolar coexistem as diferenças nas relações de gênero, assim como de classe e étnico-racial, configura-se uma abordagem necessária nas pesquisas educacionais, em uma sociedade diferenciada quanto ao acesso à educação, à cultura e aos bens materiais.

A consolidação dos alicerces do PROEJA enquanto novo campo educacional somente ocorrerá no lfes quando a proposta política do Programa convergir com a da Instituição. Não há como negar que a chegada da EJA com o EMJAT e depois com o PROEJA provocou "desordem" (OLIVEIRA; CEZARINO, 2006, p. 08) e "ranhuras" (MOURA et al., 2010, p. 02), levou, e ainda leva, a escola a (re)pensar seu lugar, seus desafios, suas práticas e sua função atual, no momento de comemoração de seu centenário e para o futuro. O PROEJA é uma realidade (im)posta, primeiramente via decreto, e depois construída pela via da luta de profissionais e estudantes que acreditam na transformação social por meio da educação. Não há quem possa questionar que:

\footnotetext{
${ }^{10}$ O projeto integrador se constituiu em um componente curricular diferente dos demais por não apresentar em sua estrutura um conteúdo prescrito ou, a priori, os mesmos nasceriam e seriam desenvolvidos a partir das vivências, experiências e saberes dos alunos e professores motivados pela necessidade de escolherem o tema gerador do projeto.
} 
a clientela do Ifes está mudando. Outras parcelas da população começam a ter acesso às suas dependências. O professor terá que se adaptar a elas para dar sentido novo ao seu trabalho. Para que isto aconteça, há uma bandeira pela qual lutar - educação de trabalhadores jovens, ou não tão jovens, com qualidade igual ou superior à que havia e ainda há para os filhos da classe média (FERREIRA, 2010, p. 18).

Nesse sentido, o próprio Programa (PROEJA) se coloca como movimento, portanto, metamorfose e travessia de uma educação compensatória para uma política pública que oferte educação de qualidade para a classe trabalhadora, constituindo-se uma conquista da sociedade civil e um horizonte utópico de uma educação transformadora.

Os caminhos da EJA, logo do PROEJA, são marcados pela heterogeneidade. E é este campo de "desordem" (SILVA, 2006) que propicia a reorganização da escola, uma vez que possibilita a experimentação de "novas formas de ser escola, potencializadoras de práticas pedagógicas inclusivas que, ao se efetivarem, diminuem as demandas para EJA" (SILVA, 2006, p. 55). Ao pensar nesta escola, não podemos nos esquivar do fato de que os próprios estudantes são partes fundamentais do processo.

Observamos que o envolvimento dentro do próprio grupo foi a primeira barreira a ser superada para a permanência e continuidade dos estudos. Os estudantes não estavam apenas vivenciando serem "os diferentes" para os outros, mas lidavam com a diversidade dentro de suas próprias salas de aula. Fácil? Eles mesmos evidenciam que não foi. Importante? Mais do que isto, necessário para o seu desenvolvimento enquanto grupo. Vejamos a experiência da aluna Sofia:

\begin{abstract}
Hoje me sinto bem, no começo foi um pouco difícil, principalmente devido à grande variedade de alunos e ao fato da diversidade de idades, comportamentos. Eu estava acostumada a estudar com pessoas da minha idade, então os assuntos eram outros, o ambiente era muito diferente, a escola era diferente. Então quando entramos é como se fosse outro mundo e tudo é jogado rápido demais e assusta um pouco. O modo como os professores lecionam é diferente. Na escola o que dá a entender, muitas vezes, está mesmo por parte de alguns professores e alunos, é que como se nós soubéssemos menos que os alunos do ensino médio normal, e isso é muito ruim, às vezes nos sentimos inferiores, eu já me senti, várias vezes. No começo já tive vergonha de falar que eu sou do PROEJA, mas hoje eu não tenho mais, com o tempo começamos a entender o que realmente é o PROEJA, mas mesmo assim tenho orgulho de estudar nessa instituição (ALUNA SOFIA).
\end{abstract}

A fala de Sofia converge com a compreensão de Ciampa (2001) sobre a totalidade parcial da personagem. Para o estudioso existe uma alternância de identidades que ocorre conforme muda o fato social; o sujeito desempenha múltiplos papéis decorrentes de sua posição no tempo-espaço. No tempo presente representa o que tem sido e, "essa expressão do outro outro que também sou eu, consiste na metamorfose da minha identidade, na superação de minha identidade pressuposta" (CIAMPA, 2001, p. 180).

A partir da análise dos dados coletados, verificamos que os alunos e alunas do PROEJA marcam suas identidades na diferença que os caracterizam enquanto grupo o que possibilita a integração dentro da diferenciação. Portanto, por serem diferentes se identificam. Segundo Heller, um dos motivos para o homem escolher fazer parte de uma comunidade é "a intenção de explicitar nela e através dela a própria individualidade" (HELLER, 1992, p. 79). Se a instituição os segrega, eles negociam continuamente com o instituído pela sua permanência, pela sua sobrevivência, pois, enquanto sujeitos, suas trajetórias foram marcadas pelo não: não-ter, não-conseguir, não-alcançar, não-ser capaz, não-poder.

Ao PROEJA Ifes Campus Vitória os educandos atribuíram a ruptura desse processo de exclusão, talvez até naturalizado em suas vidas. No tempo presente, na reta final ou com o término do curso, sentem-se capazes, poderosos, sonham e vislumbram um futuro melhor e possível, representam como autores-atores principais de suas histórias, como se a reescrevessem, não como um final, mas como um novo ciclo que se (re)inicia.

A pesquisa conheceu um pouco mais desse público que retornou ao espaço escolar e negocia constantemente com o prescrito (o Programa, a Instituição) e o vivido (o cotidiano escolar, suas experiências extraescolares e de vida). Os jovens a adultos que chegam ao PROEJA estão configurando um novo sujeito no Instituto (OLIVEIRA; CEZARINO; SANTOS, 2009, p. 11), que talvez não possa ser classificado como sujeito característico da EJA. Nem por isso este sujeito está livre de demarcações negativas sobre sua diversidade. 0 PROEJA tem um público jovem, que geralmente já frequentou o ensino médio, mas é oriundo das classes populares, com trajetórias marcadas por rupturas condicionantes em suas vidas. 
Num mundo imaginário homogêneo, as afirmações de identidades não fariam sentido (SILVA, 2008), mas esta não é a realidade do Ifes Campus Vitória. Dos sujeitos do PROEJA emergem novas subjetividades no Ifes e consigo novos desafios que requerem novas posturas da Instituição.

Portanto, a pesquisa demonstrou a necessidade de ouvir os educandos para conhecer as questões e desafios contidos no cotidiano escolar. Enquanto educadores, não podemos fazer um PROEJA para eles, devemos fazer com eles. Este é o movimento do prescrito e do vivido. Ao nos referirmos ao Programa ou à Instituição, devemos aproximá-los da realidade, pois influenciam diretamente no processo de constante metamorfose das identidades das pessoas que os formam. Neste âmbito, os resultados da pesquisa apontaram contribuições significativas na vivência dos estudantes no PROEJA Ifes Campus Vitória em suas subjetividades e emancipatórias para a continuidade de suas trajetórias de vida.

\section{REFERÊNCIAS}

ARROYO, M. G. Educação de jovens-adultos: um campo de direitos e de responsabilidade pública. In: SOARES, L.; GIOVANETTI, M.A.; GOMES, N.L. (org). Diálogos na EJA. Belo Horizonte: Autêntica, 2007, p. 69-83.

BRASIL. Congresso Nacional. Decreto n ${ }^{\circ}$ 5.840. 13 de julho 2006. Disponível em: <http://www.planalto.gov.br/ccivil_03/_Ato2004006/2006/Decreto/D5840.htm\#art11>

Acesso em: 02 fev. 2009.

CASTORIADIS, C. A instituição imaginária da sociedade. Trad. Guy Reynald. 6. ed. Rio de Janeiro: Paz e terra, 1982.

CIAMPA, A. C. A estória do Severino e a história da Severina: um ensaio de psicologia social. São Paulo: Brasiliense, 2001.

DELGADO, L. A. N. História oral: memória, tempo, identidades. Belo Horizonte: Autêntica, 2006.

FERREIRA, M. J. R. Porque é tão difícil freqüentar a escola? Escolarização e gênero feminino no EMJAT/CEFET. REUNIÃO ANUAL DA ASSOCIAÇÃO NACIONAL DE PÓS-GRADUAÇÃO E PESQUISA EM EDUCAÇÃO, 31., 2008, Caxambu (MG). Anais eletrônicos... Disponível em: <http://www.anped.org.br/reunioes/31ra/1trabalho/GT18-4408--Int.pdf>.

Acesso em: 09 jul. 2009.

FERREIRA, M. S. Quem disse que eles não podem? In: JORDANE, A. et. al. (Org.) Sala de aula em foco: caminhos para ações no Proeja. Vitória, 2010, p. 15-18.

FREIRE, P. Educação e mudança. 12. ed. Rio de Janeiro: Paz e Terra, 1983.

. Pedagogia da autonomia: saberes necessários à prática educativa. 36. ed. São Paulo: Paz e Terra, 1996.

_. Pedagogia do oprimido. 47. ed. Rio de Janeiro: Paz e Terra, 2005.

HALL, S. A identidade cultural na pós-modernidade. 11. ed. Rio de Janeiro: DP\&A, 2006.

HELLER, A. O cotidiano e a História. Trad. Carlos Nelson Coutinho, Leandro Konder. 4. ed. São Paulo: Paz e Terra, 1992.

IFES, Instituto Federal de Educação, Ciência e Tecnologia do Espírito Santo. Edital do processo seletivo simplificado 5 2009. Disponível em: <http://www.cefetes.br/internet_arquivos/Ingresso/Processo_seletivo/2009/2009_05/edital_ps_5_2009.pdf>. Acesso em: 22 Jul. 2010.

MAZOTTI, A.J.A.; GEWANDSZNAIDER, F. O método nas ciências naturais e sociais: pesquisa quantitativa e qualitativa. São Paulo: Pioneira, 1998.

MOURA, B.S. P. et al. O movimento de construção dos projetos pedagógicos dos cursos do PROEJA no IFES - Vitória/ES: avanços, tensões e desafios de um processo político. In: ENCONTRO NACIONAL DE DIDÁTICA E PRÁTICA DE ENSINO, 15., 2010. Belo Horizonte. Anais eletrônicos... Disponível em: <http://www.fae.ufmg.br/endipe/publicacoes.php>. Acesso em: 17 jun. 2010.

OLIVEIRA, E. C.; CEZARINO, K. R. A. Os sentidos do PROEJA: possibilidades e impasses na Produção de um novo campo de conhecimento na formação de professores. REUNIÃO ANUAL DA ASSOCIAÇÃO NACIONAL DE PÓS-GRADUAÇÃO E PESQUISA EM EDUCAÇÃO, 29., 2006, Caxambu (MG). Anais eletrônicos... Disponível em:

< http:www.anped.org.br/reunioes/31ra/1trabalho/GT18-4782--Int.pdf>

Acesso em: 09 jul. 2009.

OLIVEIRA, E. C.; CEZARINO, K. R.; SANTOS, J. S. Sujeitos da Educação de Jovens de Adultos no PROEJA. SIMPÓSIO BRASILEIRO DE POLÍTICA E ADMINISTRAÇÃO DA EDUCAÇÃO, 24., 2009, Vitória. Anais eletrônicos... Disponível em:

< http://www.anpae.org.br/congressos_antigos/simposio2009/88.pdf>. Acesso em: 23 jun. 2010.

OLIVEIRA, M. G. M. O CEFET-ES como não lugar: limites e possibilidades na inclusão dos alunos do PROEJA nos cursos técnicos de Edificações e Metalurgia e Materiais. 2008. Monografia (Especialização em Educação Profissional de Jovens e Adultos). Centro Federal de Educação Tecnológica do Espírito Santo, Vitória, 2008.

SILVA, E. P. Educação de Jovens e Adultos- EJA e o Programa de integração da educação profissional ao ensino médio na modalidade de jovens e adultos - PROEJA. Revista Norte científico, v.1 n.1, dez. 2006. p. 123-144.

SILVA, T. S. (org.). Identidade e diferença: a perspectiva dos Estudos Culturais. 8. ed. Petrópolis: Vozes, 2008.

_. Documentos de identidade: uma introdução às teorias do currículo. Belo Horizonte: Autêntica, 2007.

VOLPE, G. C. M. Jovens e juventude(s): questões frutíferas e prementes para educadores e pesquisadores da EJA. [s.d]. Disponível em: <http://www.fe.unicamp.br/gepeja/arquivos/Jovens_e_Juventudes-questoes_frutiferas.pdf>. Acesso em: 02 mar. 2010. 